\title{
Exploring the perception of and attitude towards preconception care service provision and utilisation in a South Western Nigerian community - A qualitative study
}

\author{
Oludoyinmola O. Ojifinni ${ }^{1}$, Pascalia O. Munyewende ${ }^{1} \&$ Latifat lbisomi $^{2,3}$ \\ ${ }^{1}$ School of Public Health, University of the Witwatersrand, Johannesburg, South Africa \\ ${ }^{2}$ Division of Epidemiology and Biostatistics, Wits School of Public Health, University of the \\ Witwatersrand, Johannesburg, South Africa \\ ${ }^{3}$ Nigerian Institute of Medical Research, Lagos, Nigeria \\ Email: oludoyinmola@gmail.com
}

\begin{abstract}
Background: Hospital-based, quantitative studies in Nigeria show low levels of knowledge and use of preconception care (PCC) services. This study explored the perception of and attitude towards PCC in a southwestern Nigerian community qualitatively.

Data Source and Methods: Focus group discussions (FGDs) were held with 57 purposively selected adult women and men and key informant interviews (KIls) with one female and one male community leader in Ibadan North Local Government Area, Oyo State, Nigeria in 2018. The FGDs and KIls held within the community were digitally recorded, transcribed verbatim and analysed thematically.

Results: Participants placed PCC in the context of marriage, describing its importance for addressing effects of adverse exposures on pregnancy and ensuring positive pregnancy outcomes.

Conclusion: Barriers to PCC uptake mentioned included lack of awareness and prohibitive service costs. Expressing their willingness to use and promote PCC use, they stated the need to ensure PCC uptake through improved awareness at the community level.
\end{abstract}

Keywords: Preconception care services; community attitudes to preconception care; context of preconception care; barriers to preconception care; willingness to use preconception care

\section{Introduction}

The World Health Organization (WHO) emphasises that the preconception period is critical in reducing pregnancy complications for women and improving birth outcomes (World Health Organization, 20I2). Evidence from life course epidemiology studies has shown that the intrauterine environment determines the risk of chronic disease in later life (Stephenson et al., 20I4; Strutz, Richardson and Hussey, 20I4; Majid, Behrman and Mani, 2019). The intrauterine environment and foetal development is influenced by factors like parental lifestyle including maternal and paternal nutritional status, diet and environmental exposures which can be modified in the preconception period (Stephenson et al., 2014; Shawe et al., 2015). In addition, evidence from both animal and human experimental epidemiological research has shown that changes in the sperm genome can occur due to men's environmental and lifestyle exposures (Braun, Messerlian and Hauser, 2017; O'Brien et al., 2018; Kothari et al., 2019; Martín-Calvo et al., 2019; Segal and Giudice, 2019).
These genetic changes have been associated with low sperm motility, increased time to pregnancy and occurrence of birth defects (Braun, Messerlian and Hauser, 20I7; Kotelchuck and Lu, 20I7; O'Brien et al., 2018; Kothari et al., 2019). The preconception period is a critical window when these lifestyle issues can be addressed while optimising both maternal and paternal health to improve reproductive health outcomes (Stephenson et al., 2014, 2018).

Preconception care (PCC) has therefore been globally advocated as part of the life-course approach to control noncommunicable diseases (World Health Organization, 2013; Stephenson et al., 2014; Poston et al., 2018). The WHO defines PCC as the provision of biomedical, behavioural and social health interventions to women and couples before conception occurs, aimed at improving their health status, and reducing behaviours and individual and environmental factors that could contribute to poor maternal and child health outcomes(World Health Organization, 2012). PCC is therefore a set of 
preventive interventions for women of reproductive age and their partners aimed at improving pregnancy outcomes (Temel et al., 20I5). The PCC package includes three core components viz: health assessment (i.e., screening), health promotion (counselling) and interventions for the treatment and management of pre-existing conditions for risk reduction (Jack et al., 2008; World Health Organization, 2012). PCC also includes reproductive life planning which assists individuals to decide if, when and how many children they want to have while ensuring health is optimized prior to conception (Dean et al., 2014; Morse and Moos, 2018). Reproductive life planning is important in the Nigerian context where cultural beliefs and fear of side effects of contraceptives have been linked with high prevalence of unplanned pregnancy (Agunbiade and Osezua, 2018). Preconception interventions have been implemented in developed countries such as the United States of America and across Europe and have the potential to mitigate many of the preventable causes of maternal and child morbidity and mortality (Stephenson et al., 20I4; Shawe et al., 2015; Temel et al., 2015). These interventions include promoting reproductive health, screening and management of chronic conditions, substance abuse and lifestyle changes, nutritional supplementation and prevention and treatment of infections (Lassi, Dean, et al., 20I4).Some countries including Australia, Hungary, Netherlands and Sweden offer PCC services at the Primary Health Care (PHC) level (Poels et al., 2017a; O'Brien et al., 2018). PHC preconception interventions include risk assessment, therapeutic (e.g. folic acid supplementation and immunisation) and behavioural (e.g. smoking cessation and exercise) interventions (Dean et al., 2013; Tuomainen et al., 2013; Lassi, Kumar, et al., 20I4).

Although interest in PCC has increased globally in the past decade, it's uptake is low or almost nonexistent in most African countries including Nigeria (Idris, Sambo and Ibrahim, 20/3; Patabendige and Goonewardene, 2013; Al-Darzi et al., 20l4; Ahmed et al., 2015; Olowokere, Komolafe and Owofadeju, 2015; Ayalew et al., 2017). Cross-sectional studies in parts of Nigeria, Ethiopia, Sudan and Egypt have linked this low uptake to lack of a specified PCC service, low utilisation of maternal health services such as antenatal care and family planning, low level of education and lack of spousal support (Al-Darzi et al., 2014; Ahmed et al., 2015; Ayalew et al., 2017; Ekem et al., 2018; Kassa and Yohannes, 2018; Abrha, Asresu and Weldearegay, 2020).

Nigeria has a need for PCC given the increasing prevalence of noncommunicable diseases among 5231 women of reproductive age which predispose them to pregnancy complications and poor birth outcomes (Federal Ministry of Health, 20I5; National Population Commission (NPC) [Nigeria] and ICF, 2019). For instance, the prevalence of hypertension among women 20 years and above was estimated at $25.2 \%$ in 2010 and projected to rise to $29 \%$ by 2030 (Adeloye et al., 2015). However, a systematic review of studies on hypertension in Nigeria reported a crude prevalence of hypertension among adult women ranging from $10 \%$ to $47.3 \%$ in 2015 (Akinlua et al., 2015). Whereas the prevalence of diabetes mellitus is estimated to be $2.8 \%$ in the general population, a review of existing records placed the prevalence of gestational diabetes at $4.2 \%$ among urban women (Ogbera, 2014; Federal Ministry of Health, 2015). Furthermore, the maternal and child health indicators in the country are unsatisfactory (Wekesah and Izugbara, 2017; National Population Commission (NPC) [Nigeria] and ICF, 2019). The maternal mortality ratio was $5 / 2 / 100,000$ live births, lifetime risk of maternal death was I in 34 , only $67 \%$ of women received antenatal care and $39 \%$ delivered in health facilities. The neonatal mortality rate was $39 / 1000$ and was highest among women who were $\leq 20$ years or $\geq 40$ years, had birth intervals $<2$ years or parity $\geq 7$ years (National Population Commission (NPC) [Nigeria] and ICF, 20I9). Having PCC can play a role in mitigating these poor reproductive health indices through optimising maternal health and reproductive life planning. In addition, PCC is recognised as a primary prevention strategy for prevention of mother to child transmission of HIV in the National Guidelines for the Prevention of Mother to Child Transmission (Federal Ministry of Health Nigeria, 2010). However, there is no specific PCC guideline while awareness and use of PCC services are low in the country as shown in previous hospitalbased cross-sectional studies by ldris, et al in the north (Idris, Sambo and Ibrahim, 20I3), Olowokere, et al in the southwest (Olowokere, Komolafe and Owofadeju, 20I5), Ekem et al in the southeast (Ekem et al., 2018) and Onasoga et al in the south-south (Onasoga et al., 20I4). A cross-sectional study among health care providers in northern Nigeria showed that while most had heard of PCC, only about a third knew up to $75 \%$ of the components while less than half had provided PCC services (Adeoye et al., 2016). When PCC services are provided, it is often in an opportunistic manner when knowledgeable patients demand for the service or when the health worker identifies a need based on a patient's reproductive history (Adesina et al., 201 I; Adeoye et al., 2016; Ojifinni and Ibisomi, 2020). The services provided in these cases include folic acid supplementation, 
counselling on lifestyle modification and screening for chronic diseases (Olowokere, Komolafe and Owofadeju, 2015; Adeoye et al., 2016; Ekem et al., 2018; Akinajo, Osanyin and Okojie, 2019).

Most of the existing literature on PCC in Nigeria mainly used quantitative methods to assess the knowledge, awareness and utilisation among pregnant women in hospital (Olowokere, Komolafe and Owofadeju, 20I5; Ekem et al., 2018) or community settings (Idris, Sambo and Ibrahim, 2013; Onasoga et al., 2014). Men play an important role in fertility issues and their fertility behaviour is often influenced by community level factors (Adewole, Adedini and Bisiriyu, 20I8). However, the opinion of men about PCC has not been documented previously although it has been shown that men's involvement and use of PCC improves the likelihood of women using the service (Kotelchuck and Lu, 2017; O'Brien et al., 2018). Furthermore, men's use of PCC services is also beneficial to their personal health (Temel et al., 2015; O'Brien et al., 2018; Kothari et al., 2019). However, the belief that men are not interested in fertility issues hampers their inclusion in reproductive health research (Grace et al., 2019). This article was part of a larger study exploring the need for and feasibility of PCC in Nigeria. To achieve broader aim, this study was designed as a situation analysis describing what is known at the community level to identify the gaps that need to be filled in promoting uptake of PCC within the community. This study therefore used qualitative methods to explore perception of and attitude towards PCC service provision and utilisation among women and men in a southwestern Nigerian community.

\section{Data and methods}

\section{Study setting}

This qualitative explorative study was carried out in Yemetu Ward 3 of Ibadan North Local Government Area (LGA) of Ibadan, Oyo State Nigeria. Nigeria is divided into 36 states and Oyo State is in the southwestern part of the country. The state is divided into 33 LGAs for administrative purposes. lbadan North LGA is one of the five urban LGAs within the Ibadan metropolis which is the state capital. The Nigerian health system operates at three levels - the primary, secondary, and tertiary in increasing order of specialisation. The Yemetu Ward 3 of Ibadan North LGA was selected because of the presence of the three levels of healthcare: The University College Hospital - a tertiary health facility, Adeoyo Maternity Hospital - a secondary health facility as well as II primary healthcare centres. All the facilities provide maternal and child health care services.

\section{Study population}

The total study population of 59 participants included 23 women aged 18 to 49 years and 22 men aged 18 to 59 years within the selected community; one female and one male community leader who are both members of the Ward Development Committee (which oversees the activities in the primary healthcare centre); as well as seven Christian and five Muslim clergy who provided premarital counselling within their religious groups. Anecdotal reports show that premarital counselling often includes discussions around the couple's plan for pregnancy and childbirth which may include preconception health information.

\section{Recruitment of participants}

The community members were purposively selected from Yemetu Ward 3 of Ibadan North LGA with the assistance of the male and female community leaders and grouped by sex, educational and marital status. In addition, the secretary of the Christian Association of Nigeria in the LGA assisted in recruiting volunteers among the Christian clergy while the male community leader assisted in recruiting Muslim clergy using a snowball approach.

\section{Data collection procedure}

This study collected information using focus group discussions (FGDs) among women, men, and religious leaders while key informant interviews (KIls) were conducted with community leaders. The interview guides focused on awareness, and perception about PCC services and its utilisation. The participants were asked what they understood by the term "preconception care" then they were provided with the definition of PCC obtained from literature and asked the following questions: (I) Having heard the description of preconception care, do you believe it is necessary to have preconception health and care as part of the maternal and child health services in your community? (2) Would you be willing to use or support the use of such a service? (3) In your opinion, would women and men in the community be willing to use such a service? (4) Do you think your community would be willing to support the use of such a service? Responses to the questions were probed as needed during the interviews.

Four Master's students from the Faculty of Public Health, University of Ibadan who had been involved in qualitative data collection were trained to assist in the data collection and supervised by the first author. They worked in two teams composed of one male and one female and used open-ended interview guides. While one of the team members facilitated the discussion, the other made field notes which were later integrated into the transcripts. Eight FDGs were held with the adult women and men, 
disaggregated by sex, marital and educational status (Figure I). Each group had between five and eight participants.

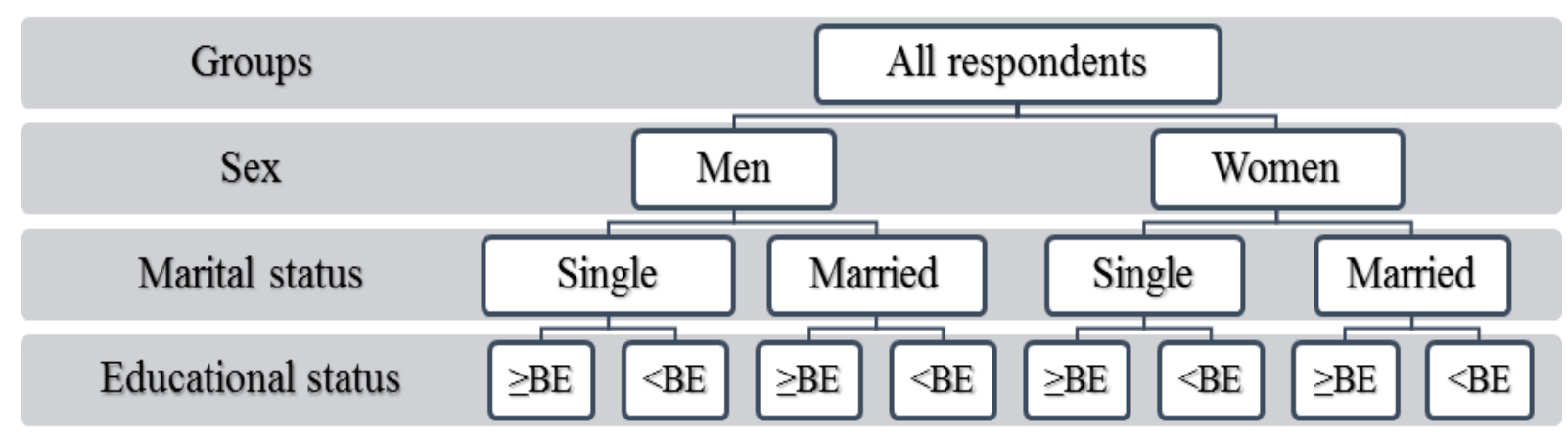

Figure I Disaggregation of study participants (BE - Basic education, nine years of schooling (also referred to as junior secondary school)).

Further, one FGD with the Christian religious leaders and one with Muslim clergy while Klls were held with two community leaders - one female and one male. In total, there were 10 FGDs and two Klls. All were conducted at venues within the community selected by the participants and digitally recorded. The data collection took place between April and December 2018. The interview questions were based on PCC literature and reviewed by experts in qualitative research. The guides were pretested, and ambiguous questions were rephrased. Interview guides were translated into Yoruba (the local language of the area) by a professional service and back-translated to ensure consistency of meaning. The interviews were conducted in Yoruba or English depending on the participants' preference and the FGDs lasted about 45 minutes to one hour while the KIls lasted between 25 and 30 minutes. The twelve audio recordings were transcribed verbatim (and translated into English where necessary).

\section{Data management and analysis}

All transcripts were deidentified, labelled with codes and stored in a password-protected laptop to which only the research team had access. Thematic analysis of the data was done using a hybrid of inductive and deductive coding on all the transcripts (Braun and Clarke, 2006; Fereday and Muir-Cochrane, 2017). Deductive codes were prepared from previous literature and the study objectives while inductive codes were identified while reading the data. These codes were merged during analysis in the fifth step of the six phases of thematic analysis namely familiarisation with the data, generating initial codes, searching for themes, reviewing themes, defining and naming themes and producing the report (Braun and Clarke, 2006). The twenty-two codes generated were collated into six themes that formed the codebook. Data triangulation was used by convergence of information from the diverse groups of participants for defining the themes. All the data analysis was done using MAXQDA software for qualitative data analysis (VERBI Software, 20I7).

\section{Ethical considerations}

Information sheets with the study details were provided to the participants. All participants understood that they could withdraw from the study at any time. Consent forms were signed for participation in the interviews and for voice recording. Ethical approval was obtained from the Oyo State Ministry of Health Ethics Committee in September 2017 (Approval number AD/I3/479/565) and from the Wits Human Research Ethics Committee (Medical) in March 2018 (Clearance certificate number MI 7 I054).

\section{Results}

There were more females 23 and males 22 among the participants. The participants were all between 18 and 59 years. Among the FGD participants, there were 10 single women, 12 single men, 13 married women and 10 married men. All the married participants had children. About one-third of the participants had less than junior secondary education. There were 17 traders, 13 artisans and 12 students among the community members. The six themes identified from the discussions/interviews are shown in Table I. 
Table I Focus group discussion and key informant interview themes

Theme Sub-themes/Description

Perception about preconception care Context of preconception care

Description of preconception care

Perception about the importance of Importance of preconception care

and need for preconception care Who needs preconception care?

Men's need for preconception care

Potential benefits of preconception care

Opinions about what preconception Issues to address in the preconception period

care should cover

Addressing existing health conditions

Possible barriers to the use of

Description of hindrances to the use of preconception care services

preconception care services

Willingness to use and support the use Participants' willingness to use preconception care services

of preconception care services

Opinion about use of preconception care services in the community

Willingness to support the use of preconception care services in the

community

\section{Perception about preconception care}

\section{Context of preconception care}

Anecdotally, pregnancy is culturally expected and acceptable only within marriage in most Nigerian communities. Hence most of the discussions centred around PCC for couples planning marriage or already married.

"We expect that 9 to 10 months after a couple's wedding, we should congratulate them on safe delivery. ...." [Muslim Clergy FGD, P5]

"For you to think that you want to conceive, it means that you are married. ... There are some medical issues that are obstacles to childbearing. The woman and her partner need to visit the hospital to find out if they are compatible in terms of their Rhesus factor, their blood group and their genotype". [Single women FGD, $\geq B E, P 3$ ]

\section{Description of preconception care}

The participants understood PCC to be care needed in preparation for pregnancy which included medical check-up. While medical check-up can be assumed to capture screening for chronic conditions, a component of the WHO package of $\mathrm{PCC}$, there is more to the components than what the participants described. Other measures described as non-medical activities such as husbands' care for their wives, pampering and ensuring avoidance of stressful activities in preparation for pregnancy are not part of the components of PCC.

"It is the care where a woman does medical check-up before she gets pregnant ..." [Community Leader, Woman]

"I think preconception care actually means necessary activities including both medical and non-medical activities the couple preparing for pregnancy should undergo to ensure a smooth process when the time of getting pregnant comes". [Single women FGD, $\geq B E, P 2$ ]

"That's the normal care you give to your wife before she conceives. I believe preconception care should start immediately after marriage. You know, all manner of pampering, for a lady not to stress herself, make your wife happy by buying good stuff for her, taking her out. That's my own understanding". [Married men FGD $\geq B E, P 2$ ]

Participants also stated that while the term PCC appears to focus only on women, the service should be for women and men to detect and treat any health problems ahead of marriage since they are both involved in the process of childbearing.

"I think hearing the word preconception to laymen, they will think that it's strictly for ladies. And it is beyond that. This preconception care is 
supposed to be for both men and ladies that are intending to be fathers or mothers in the future". [Single women FGD, $\geq B E, P I]$

“.... This care needs to be carried out before couples get married at all". [Married men FGD, $\geq B E, P 5]$

Perception about the importance of and need for preconception care

In describing the need to have preconception care, the participants expressed their opinion about the importance of PCC services identifying people who they believed may need PCC and sharing their views on its potential benefits.

\section{Importance of preconception care}

The participants stated their opinion about the importance of adequate care before pregnancy, expressing the view that PCC is needed for women who may have experienced certain exposures that may compromise their health and affect pregnancy outcomes.

"What we are talking about here is preconception care which we don't really take as important in Nigeria and in Africa. ... I think if we have more awareness about preconception care in our local community and beyond, things will be better". [Married men FGD, $\geq B E, P 5]$

"PCC is especially important, but our community members don't know, and it is endangering their lives. The lifestyle of many women before they get pregnant has compromised their health ... and this endangers them when they get pregnant". [Christian Clergy, FGD, PI]

The importance of PCC for pregnancy planning, preventing unwanted pregnancy and avoiding unsafe abortions was discussed among the single women. They believed when a couple has made adequate plans on when they desire pregnancy, complications associated with unwanted pregnancies can be avoided.

"I think the couple has to avoid abortions. If they are not ready to be parents, they should not go into premarital sex. Because once the lady gets pregnant $\ldots$ and they abort, this may hinder them from having a child in the future. With preconception care, they can plan better and avoid unwanted pregnancy" [Single women FGD, $\geq B E, P I]$

Another reason the participants believed PCC is important is that it helps in identifying potential problems in either the man or the woman, which 5235 may prevent a couple from achieving their pregnancy intentions or lead to infertility. Timely identification of the problem and provision of adequate treatment to the affected party can be done through preconception care. PCC was also described as being important because the baby's health depends on the mother's.

"It is important for the couple to go for check-up before marriage ... There are some women and men with health problems that ... if the check-up had been done right from the onset, they would have been informed about their partner's inability to give birth". [Single men FGD, <BE, P7]

"... the woman must receive proper care and be in good health before pregnancy otherwise it will be like putting the cart before the horse ..." [Christian Clergy FGD, P2]

"... the care of the baby depends on the mother. ... If the mother ... eats well balanced diet and does other necessary things at the appropriate time, the baby will be healthy". [Single men FGD, $<B E, P 3]$

The importance of checking a couple's genetic compatibility and determining their blood group, genotype and rhesus status prior to pregnancy was also emphasised. The danger of having children with the sickle cell disorder was mentioned.

"It is important for a couple to know about preconception care when planning to get pregnant because both of them may belong to the blood group AS. So, they won't be caught unawares that their baby is SS at the eleventh hour". [Single men FGD, <BE, PI]

"In terms of compatibility, rhesus compatibility can affect or lead to spontaneous abortion even if the person gets pregnant. This too can be checked through preconception care" [Married men FGD, $\geq B E, P 4]$

"We have heard stories of babies who died immediately after birth or not too long after in the past. ... That should not happen these days because we are learned. Immediately we start courting, the counselling and necessary tests should also be done". [Married men FGD, $\geq B E$, PI]

\section{Who needs preconception care?}

Participants expressed the opinion that women, men, and couples require PCC. In particular, they mentioned couples who had just begun courtship or http://aps.journals.ac.za 
were newlywed as needing PCC to identify and address potential problems early.

"Those who are planning to get pregnant, those that are married, those that are pregnant already and those that have even given birth and are still planning to have another baby all need preconception care". [Single women FGD, $<B E$, P3]

"Well, I will say preconception care is for couples. It is needed immediately they start courting. Once they start courting, they need counselling because they have to know each other's status". [Married men FGD, <BE, $P I]$

\section{Men's need for preconception care}

There were differing opinions regarding men's need for preconception care. Some participants believed that men's preconception health is important. Others, particularly the married men felt that men do not need any form of care in the preconception period. One of the participants referred to such care as "pampering" which is not necessary because men should be tough and provide for their families.

"It is important to consider the health status of the man. I have heard about men with low sperm count which can prevent them from getting a woman pregnant. A man needs to look into that. They also need good hygiene and proper nutrition ... Then if a man's occupation causes some kind of stress it may affect him getting his wife pregnant". [Single women FGD, $\geq B E, P 2$ ]

"Either one is married or not married, it is good to receive preconception care. I liked eating sweets until a nurse told me that it causes watery sperm. In the case of a couple, they should know their medical conditions. For instance, the husband may have low sperm count that may lead to infertility". [Single men FGD, <BE, PI]

"For men, the number one thing is you need to go out there, find what the family will eat and keep yourself safe. There is no need for any special care or pampering. As far as you are perfectly okay, I don't think there is any necessary care again for a man". [Married men FGD, $\geq B E$, P5]

Participants opined that the kind of social and environmental exposures men have in the preconception period could affect pregnancy plans negatively. They stated that men who intend to get their wives pregnant should avoid substance use including alcohol and tobacco. They believed men must avoid multiple sexual partnerships which may predispose them and their wives to infections. and maintain their scrotal temperature within acceptable limits to ensure good sperm integrity.

"What a man eats can prevent him from getting a woman pregnant because if a man desires a child and engages himself in excess drinking of alcohol, smoking or taking some dangerous substances he will find it difficult to have a child. Also, a man who is a notorious womanizer, will find it difficult to get a woman pregnant". [Married men FGD, $\geq B E, P 3]$

"The man planning conception with his wife should avoid extramarital affairs; he can become infected and transmit the infection to his wife. $\mathrm{He}$ should also avoid alcohol consumption and eat moderately. Bad eating habit is harmful to the man's health, the woman's health and eventually affect the baby". [Married women FGD, $\angle B E$, PI]

"I will talk about the temperature in terms of clothing and occupation. The temperature of the scrotum affects the survival of the sperm cells. For example, if someone is a long-distance driver, the temperature of the heat from engine can affect the quality of the sperm cells. Also, the emissions from the use of laptops and tight clothing can affect the quality of sperm and when that happens, getting a woman pregnant will be difficult". [Married men FGD, $\geq B E, P 4$ ]

The married women stated that men's need for medical check-up in the preconception period may depend on findings of their partners' check-up.

"It is not as if both of them will go \{for check-up\} at the same time. It is the wife's diagnosis - the result of her test that determines whether the husband will be called upon". [Married women $F G D,<B E, P 3]$

\section{Potential benefits of preconception care}

The participants expressed their belief that PCC reduces the likelihood of delayed conception, complications in pregnancy like recurrent stillbirths, and increases the chances of a positive outcome.

"Preconception care is especially important as it is the foundation for both the woman and the man to make the journey of pregnancy easy. It will minimize the occurrence of many complications during pregnancy and lead to positive outcomes at delivery". [Christian Clergy, FGD, PI]

"With preconception care, delay in getting pregnant will not be there or when they want to give birth, even after giving birth there won't be any problem for the child because both the 
husband and wife have taken care of themselves". [Married women FGD, $\geq B E, P 4]$

With the identification and treatment of pre-existing health problems through PCC, participants believed that subsequent pregnancies are more likely to result in healthy babies. In addition, the doctor and parents can plan and prepare ahead for potential health challenges in the baby when s/he is born.

"Then there will be no trouble or anxiety about what their child will be like. The health of the child will be assured as stated in the Quran. If they eat healthy food and drink good water, and they live in a good environment, they will have confidence in their own health and be well assured that both the man and the woman can be parents because they know their state of health is adequate”. [Muslim Clergy FGD, P4]

"If a couple that wants to get pregnant realize they have a health challenge, they should go to the hospital and do a check-up. The doctor will give the right diagnosis and appropriate treatment to both of them and advise them on the type of treatment the child may need after delivery". [Community Leader, Woman]

"For women with HIV, they will start taking care of them from the early stage of pregnancy. I have a close relative that went for this before she got pregnant. ... If it had been someone that did not have any check-up, it would have spread to the baby". [Married women FGD, $\geq B E, P 4]$

"When you have the care, your mind will be at peace. ... And for the man as well, his mind will be at rest that ... I should be able to get my wife pregnant. And the woman is at rest that her baby will be healthy". [Single women FGD, $\geq B E, P 4]$

\section{Opinions about what preconception care should} cover

Participants expressed their opinions on health and non-health issues that can be addressed in the preconception period. The participants also mentioned methods of addressing the health conditions identified through medical check-up or screening.

\section{Issues to address in the preconception period}

The participants mentioned the need for newly married or intending couples to go for counselling. They believed this counselling should include encouraging medical check-up and discussing timing of sexual intercourse. Participants also stated their 5237 belief in the importance of women paying attention to their nutrition and hygiene as well as avoiding stressful activities, substance abuse and selfmedication in the preconception period.

"The couple should go for counselling. I think there are some groups of people that do counselling about how to make babies and the things you are supposed to do during that period". [Single women FGD, $\geq B E, P 4]$

"A woman should keep herself safe and not do difficult jobs and watch her eating habits during her ovulation period. She needs to know the time of her ovulation and she needs to exercise". [Married men FGD, <BE, P2]

“Concerning men's health. ... Sometimes they have sex with their wives with the eagerness that "I want to get my wife pregnant" but they don't know the actual time when she's likely to get pregnant. I think they still need medical advice about that". [Single women FGD, <BE, P3]

"I think for both the man and the woman, one of the primary things that they should not do at all is consumption of alcohol or use medications without being prescribed by their physicians. That is important for both parties". [Single women $F G D, \geq B E, P 2]$

"A woman must take caution with the consumption of medications before and during pregnancy. Even before pregnancy, she should not take just any drug. ..." [Married women FGD, $<B E, P 5]$

"We must maintain high level of cleanliness and we must create some time to rest. This is important for both the man and his wife. We must eat nourishing food like vegetables and fruits". [Married women FGD, $\geq B E, P 2]$

\section{Addressing existing health conditions}

The treatment of infections and other health conditions, use of folic acid, couple's genotype, rhesus and HIV status determination and diagnosis of hypertension made up the discussion on addressing pre-existing health conditions through PCC.

"There are some cases where a couple will not achieve pregnancy because they have not identified their problem. What they must do is go for test, ..., and if there is any \{problem\}, receive adequate treatment". [Married women FGD, $<B E, P 2]$ 
"A woman who is hypertensive before pregnancy may have a dangerous pregnancy. ... These things must be taken care of before the woman gets pregnant”. [Christian Clergy FGD, P2]

“... HIV test and other blood tests, urine test must be done and checking of blood pressure because hypertension is a popular thing now". [Married women FGD, $\geq B E, P 4]$

"In preconception care ... you can talk about the actual preparation of the reproductive system getting rid of infections like urinary tract infections using antibiotics and also the use of folic acid". [Married men FGD, $\geq B E, P 4]$

Possible barriers to the use of preconception care services

In identifying possible barriers to PCC use, participants believed the assumption that hospital services are costly, hospital protocols and processes and fear of the outcome of their medical check-up may prevent people from accessing the service. Other barriers identified include cultural views about hospital services, preference for traditional medicine providers, religious beliefs, and lack of awareness of PCC and its potential benefits.

"Many people assume that the hospital expenses are too high. Some say that their ancestors did not go to hospitals, see any doctors, or receive any injections so they can use herbs to take care of the pregnancy, but this is inadequate knowledge. This is what the doctors were trained for. [Christian Clergy, FGD, P6]

"... They might even make jest that "what is this program meant for?" because they are not aware of the benefits. Some people are afraid of knowing their health status. ... Also, the norms, customs and religious beliefs of the people in the society may make them feel that this \{preconception care $\}$ is not welcome". [Single women FGD, $\geq B E, P I]$

"In the hospitals, there are a lot of protocols and things that must be done before a woman can be attended to. This may be viewed negatively and lead to people not wanting to use the service". [Single men FGD, <BE, P4]

Willingness to use and support the use of preconception care services

Many of the participants expressed their willingness to support and use PCC services if it is provided in their community.
"If such a program exists in our community, I as a person will support it because we don't have to go far to get such a beneficial service". [Single men FGD, $\geq B E, P 3]$

Participants also gave their opinion on possible community support for PCC services and the need to raise awareness about the importance of PCC. They believed increased awareness will improve the willingness to support and use PCC.

"Our community will be willing to use and support the program because it is part of precautions against unwanted medical situations. Those who don't understand will say no and those who understand and know what it $\{P C C\}$ means will say yes. If the majority say yes, then everybody will agree. That is why it is good to make them aware of the program". [Married men FGD, $\geq B E, P 3]$

The community and religious leaders stated their willingness to include PCC in the premarital counselling they provide to couples who are about to wed. They expressed the opinion that everyone who is aware of the importance of PCC should spread the information within their spheres of influence.

"I am one of the Ward Health Committee members for the health centres that care for pregnant women in this community. It is particularly important that I give advice on preconception care because in this community, we take anything relating to health as serious and important". [Community Leader, Man]

"If everyone who understands the importance of preconception care through western education or religion either Muslim or Christian shares the knowledge with the people around them, starting with their immediate family, the information will begin to go around. The whole community will be well informed till it covers the whole society and in the long run the nation". [Muslim Clergy FGD, P3]

\section{Discussion}

This study explored the perceptions about and attitudes towards preconception care (PCC) among women and men in a Nigerian community. The novelty in this study is the inclusion of male voices in the discussion of PCC which has not been done in previous studies in the country. The participants gave their opinions on what they believed PCC is, describing its components and highlighting its importance and benefits to potential parents. There was general awareness of PCC, its importance and relevance to women and men and the potential 
benefits to families and communities. The level of understanding of PCC among the participants contrasts with the low awareness recorded in previous studies in the country (Idris, Sambo and Ibrahim, 2013; Lawal and Adeleye, 20I4; Onasoga et al., 2014; Olowokere, Komolafe and Owofadeju, 2015; Adeoye et al., 2016; Ekem et al., 2018). Demonstrating an awareness of the requirements for optimal preconception health, the participants enumerated medical and non-medical preparations for pregnancy. Highlights of the discussions included addressing specific health issues in the preconception period; ensuring adequate nutrition; avoiding exposures that can have negative health impacts such as alcohol and substance abuse; maintaining good hygiene and planning for childbearing. These measures are consistent with the components of PCC described in literature (Dean et al., 2013; Lassi, Kumar, et al., 2014).

Regarding whom PCC should be provided for, participants stated that preconception preparations are essential for both women and men who intend to have children although, the term PCC appears to be targeted at women. While some of the men in our study believed that PCC includes pampering 'delicate women' and is not necessary for men, others identified the possibility of low sperm count which may affect pregnancy intention as necessitating PCC for men. These resonate with some European studies that showed lack of awareness of the biological importance of paternal preconception health (McGowan et al., 2020) and the importance of PCC for men to address exposures and lifestyle changes (Tuomainen et al., 2013; Poels et al., 2017b). Previous studies have also shown that men would benefit from PCC for reproductive life planning, health risk assessment, health promotion and interventions to optimise their health (Frey et al., 2008; Choiriyyah et al., 2015; Garfield, 2018). In addition, PCC for men is also beneficial as it increases the likelihood of their female partners adhering to recommended lifestyle changes for improving preconception health (Choiriyyah et al., 2015; O'Brien et al., 20I8). It is therefore important to continue to engage men in the discussion on PCC and incorporate their needs into PCC deployment in the country.

Furthermore, individuals who have known health problems were specifically mentioned as requiring PCC to optimise their health before pregnancy. This included persons with HIV, hypertension, diabetes, and sickle cell disorder. The potential for reduction of delay in achieving pregnancy and addressing causes of infertility were also mentioned as instances where PCC can be useful. The prevalence of the sickle cell trait in Nigeria is $24 \%$ while about $2 \%$ of the population is living with sickle cell disorder (Federal Ministry of Health, 2015). Health challenges associated with sickle cell are therefore a reality for many of the participants and may explain its emphasis in the discussions. The issue of assessing compatibility before marriage was also well discussed. In addition, the increasing prevalence of these chronic noncommunicable diseases in the country (Macaulay, Dunger and Norris, 20I4; Ogbera, 2014; Adeloye et al., 2015; Federal Ministry of Health, 2015) means that many of the participants have relatives on treatment for one or the other. Hence the consciousness of the health implications of such diseases in the discussions. This awareness can be a starting point for promotional campaigns on the need for PCC in the country.

The participants described benefits of having PCC for the parents, neonates and the community stating that treatment of identified health problems in the preconception period minimises the risk of complications during pregnancy and at delivery and improves the chances of positive pregnancy outcomes. Other studies have also shown that preconception interventions improve maternal health and birth outcomes (Tuomainen et al., 2013; Beckmann, Widmer and Bolton, 2014; Hussein, Kai and Qureshi, 2016; Brown et al., 2017; Poels et al., $2017 \mathrm{~b})$. In promoting PCC deployment in the country, the potential benefits as understood at the community level can be leveraged in the design of awareness campaigns.

Participants in the study felt that greater awareness and understanding of the benefits of PCC will influence the use of the service. However, they identified potential barriers to use to include cost of the service, hospital protocols and processes, cultural and religious beliefs, lack of awareness of the potential benefits, and fear of the possible outcomes of medical screening. Other studies have also identified similar barriers to the use of PCC services. Cultural and religious barriers, hospital protocols, lack of awareness of PCC and its benefits, and fear of the result of health screening have also been described as barriers to PCC use in other studies (Tuomainen et al., 2013; Bayrami et al., 2016; Bortolus et al., 2017; Poels et al., 2017b). It is important to bear these potential barriers in mind in the design and deployment of PCC services in the country.

\section{Conclusion}

This study shows that there is an understanding of the importance of preconception health and the need for PCC particularly for women at the community 
level in southwest Nigeria. There is also a positive attitude towards the use of PCC services although such services are not yet routinely available in the country. The fact that there is already some awareness of PCC, its importance and benefits at community level can be leveraged on in deploying routine PCC services. There is however a need to ensure awareness is raised on the biological importance of paternal preconception health especially among the men.

\section{References}

Abrha, M. W., Asresu, T. T. and Weldearegay, H. G. (2020) 'Husband Support Rises Women's Awareness of Preconception Care in Northern Ethiopia', The Scientific World Journal, pp. I-7. doi: 10.1 155/2020/34I5795.

Adeloye, D. et al. (2015) 'An estimate of the prevalence of hypertension in Nigeria', Journal of Hypertension, 33(2), pp. 230-242. doi: I0.1097/HJH.00000000000004/3.

Adeoye, T. O. et al. (20/6) 'Awareness and perception of preconception care among health workers in Ahmadu Bello University Teaching University, Zaria', Tropical Journal of Obstetrics and Gynaecology, 33, pp. 149-152. doi: 10.4103/0189-5117.192215.

Adesina, K. et al. (20II) 'Pregnancy outcome of the obese in Ilorin', Obstetric Medicine, 4(4), pp. 160-163. doi: 10.1258/om.20I I.10008I.

Adewole, O. G., Adedini, S. A. and Bisiriyu, L. A. (2018) 'Multilevel analysis of male fertility behaviour in Nigeria', African Population Studies, 32(3), pp. 1689-1699. doi: I0.1 I564/32-3-1224.

Agunbiade, O. M. and Osezua, C. O. (2018) 'Fear of contraceptives' side effects and tensions in marital union among women at risk for unintended pregnancy in southwest Nigeria', African Population Studies, 32(3). doi: 10.1/564/32-31242.

Ahmed, K. Y. M. et al. (2015) 'Knowledge, Attitude and Practice of Preconception Care Among Sudanese Women in Reproductive Age About Rheumatic Heart Disease Knowledge , Attitude and Practice of Preconception Care Among Sudanese Women in Reproductive Age About Rheumatic Heart Disease', Basic Research Journal of Medicine and Clinical Sciences, 4(7), pp. 199x 203.

Akinajo, O. R., Osanyin, G. E. and Okojie, O. E. (2019) 'Preconception care: Assessing the level of awareness, knowledge and practice amongst pregnant women in a tertiary facility', Journal of Clinical Sciences, 16(3), pp. 87-92. doi: I0.4I03/jcls.jcls_4I_I8.
Akinlua, J. T. et al. (2015) 'Current prevalence pattern of hypertension in Nigeria: A systematic review', PLoS ONE, IO(I0), pp. I-18. doi: I0.1371/journal.pone.014002I.

Al-Darzi, W. et al. (2014) 'Knowledge of periconceptional folic acid use among pregnant women at Ain Shams University Hospital, Cairo, Egypt.', Eastern Mediterranean health journal = La revue de sante de la Mediterranee orientale = al-Majallah al-sihhiyah li-sharq al-mutawassit, 20(9), pp. 56I-568.

Ayalew, Y. et al. (2017) 'Women's knowledge and associated factors in preconception care in Adet, West Gojjam, Northwest Ethiopia: a community based cross sectional study', Reproductive Health, I4(I), p. I5. doi: |0. I | 86/s | 2978-0| 7-0279-4.

Bayrami, R. et al. (2016) 'Experiences of women regarding gaps in preconception care services in the Iranian reproductive health care system: A qualitative study', Electronic Physician, 8(I I), pp. 3279-3288. doi: 10.19082/3279.

Beckmann, M. M., Widmer, T. and Bolton, E. (2014) 'Does preconception care work?', Australian and New Zealand Journal of Obstetrics and Gynaecology, 54(6), pp. 5|0-5|4. doi: I0. I I I I/ajo. 12224.

Bortolus, R. et al. (2017) 'Why women do not ask for information on preconception health? A qualitative study', BMC Pregnancy and Childbirth, I7(5), p. II. doi: I0. I 186/s I 2884-0I6-I I98-z.

Braun, J. M., Messerlian, C. and Hauser, R. (2017) 'Fathers Matter: Why It's Time to Consider the Impact of Paternal Environmental Exposures on Children's Health', Current Epidemiology Reports, 4(I), pp. 46-55. doi: I0.1007/s4047I0I7-0098-8.

Braun, V. and Clarke, V. (2006) 'Using thematic analysis in psychology', Qualitative Research in Psychology. Edited by Intergovernmental Panel on Climate Change, 3(2), pp. 77-I0I. doi: I0.1 I9I//478088706qp063oa.

Brown, H. K. et al. (20I7) 'Preconception health interventions delivered in public health and community settings: A systematic review', Canadian Journal of Public Health, 108(4), pp. e388-e397. doi: 10.17269/cjph.108.6029.

Choiriyyah, l. et al. (2015) 'Men Aged I5-44 in Need of Preconception Care', Maternal and Child Health Journal, 19(II), pp. 2358-2365. doi: 10.1007/s 10995-0I5-I753-7.

Dean, S. $V$ et al. (20/3) Systematic Review of Preconception Risks and Interventions.

Dean, S. V et al. (20/4) 'Preconception care: promoting reproductive planning', Reproductive Health, II(Suppl 3), p. S2. doi: 10.1/86/17424755-I I-S3-S2. 
Ekem, N. N. et al. (2018) 'Utilisation of preconception care services and determinants of poor uptake among a cohort of women in Abakaliki Southeast Nigeria', Journal of Obstetrics and Gynaecology, 38(6), pp. 739-744. doi: 10.1080/0I4436I5.2017.1405922.

Federal Ministry of Health (2015) National Strategic Plan of Action on Prevention and Control of NonCommunicable Diseases.

Federal Ministry of Health Nigeria (2010) National Guidelines for Prevention of Mother-to-Child Transmission of HIV (PMTCT). Fourth. Abuja, Nigeria: HIV and AIDS Division, Federal Ministry of Health, Nigeria.

Fereday, J. and Muir-Cochrane, E. (2017) 'Demonstrating Rigor Using Thematic Analysis: A Hybrid Approach of Inductive and Deductive Coding and Theme Development', International Journal of Qualitative Methods, 5(I), pp. 80-92. doi: 10.1 I 77// 60940690600500I07.

Frey, K. A. et al. (2008) 'The clinical content of preconception care: preconception care for men', American Journal of Obstetrics and Gynecology, 199(6), Pp. S389-S395. doi: 10.1016/j.ajog.2008.10.024.

Garfield, C. F. (2018) 'Toward Better Understanding of How Fathers Contribute to Their Offspring's Health', Pediatrics, I4I(I), p. e2017346I. doi: 10.1542/peds.2017-346I.

Grace, B. et al. (2019) 'You did not turn up... I did not realise I was invited...: understanding male attitudes towards engagement in fertility and reproductive health discussions', Human Reproduction Open, 2019(3), pp. I-7. doi: 10.1093/hropen/hoz0I4.

Hussein, N., Kai, J. and Qureshi, N. (2016) 'The effects of preconception interventions on improving reproductive health and pregnancy outcomes in primary care: A systematic review', European Journal of General Practice, 22(I), pp. 42-52. doi: $10.3109 / 138 \mid 4788.2015 .1099039$.

Idris, S. H., Sambo, M. N. and Ibrahim, M. S. (20I3) 'Barriers to utilisation of maternal health services in a semi-urban community in northern Nigeria: The clients' perspective', Nigerian Medical Journal, 54(I), p. 27 . doi: 10.4103/03001652. 108890.

Jack, B. W. et al. (2008) 'The clinical content of preconception care: an overview and preparation of this supplement', American Journal of Obstetrics and Gynecology, 199(6), pp. S266S279. doi: 10.1016/j.ajog.2008.07.067.

Kassa, A. and Yohannes, Z. (20/8) 'Women's knowledge and associated factors on preconception care at Public Health Institution in
Hawassa City, South Ethiopia', BMC Research Notes, II(I), p. 84I. doi: I0.II86/s|3I04-0I8$395 \mathrm{I}-\mathrm{z}$.

Kotelchuck, M. and Lu, M. (2017) 'Father's Role in Preconception Health', Maternal and Child Health Journal, 2I(II), pp. 2025-2039. doi: I0.1007/s 10995-017-2370-4.

Kothari, A. et al. (2019) 'The forgotten father in obstetric medicine', Obstetric Medicine, 12(2), pp. 57-65. doi: 10.1 I77/1753495X18823479.

Lassi, Z. S., Kumar, R., et al. (20/4) 'Essential interventions: implementation strategies and proposed packages of care', Reproductive Health, I I(Suppl I), p. S5. doi: I0. I I86/I742-4755-I I-SIS5.

Lassi, Z. S., Dean, S. V, et al. (2014) 'Preconception care: delivery strategies and packages for care', Reproductive Health, II(Suppl 3), p. S7. doi: 10.1 I86/1742-4755-II-S3-S7.

Lawal, T. A. and Adeleye, A. O. (2014) 'Determinants of folic acid intake during preconception and in early pregnancy by mothers in Ibadan, Nigeria', Pan African Medical Journal, 19, pp. 1-6. doi: 10.1 1604/pamj.2014.19.113.4448.

Macaulay, S., Dunger, D. B. and Norris, S. A. (2014) 'Gestational diabetes mellitus in Africa: A systematic review', PLoS ONE, 9(6), pp. I-II. doi: 10.1371/journal.pone.009787I.

Majid, F., Behrman, J. and Mani, S. (2019) 'Short-term and long-term distributional consequences of prenatal malnutrition and stress: using Ramadan as a natural experiment', BMJ Global Health, 4(3), p. e00। I85. doi: I0. I I36/bmjgh-20।8-00। I85.

Martín-Calvo, N. et al. (20/9) 'Paternal preconception folate intake in relation to gestational age at delivery and birthweight of newborns conceived through assisted reproduction', Reproductive BioMedicine Online, 39(5), Pp. 835-843. doi: 10.1016/j.rbmo.2019.07.005.

McGowan, L. et al. (2020) 'Exploring preconception health beliefs amongst adults of childbearing age in the UK: a qualitative analysis', BMC Pregnancy and Childbirth, 20(I), p. 4I. doi: 10.1 I86/s I2884-0202733-5.

Morse, J. E. and Moos, M. K. (2018) 'Reproductive Life Planning: Raising the Questions', Maternal and Child Health Journal, 22(4), pp. 439-444. doi: 10.1007/s 10995-018-25 I6-z.

National Population Commission (NPC) [Nigeria] and ICF (2019) Nigeria Demographic and Health Survey 2018. Abuja, Nigeria and Rockville, Maryland, USA. 
National Population Commission [Nigeria] and ICF Macro (2009) Nigeria Demographic and Health Survey 2008. Abuja, Nigeria.

O'Brien, A. P. et al. (20I8) 'Men's Preconception Health: A Primary Health-Care Viewpoint', American Journal of Men's Health, 12(5), pp. |575-|58|. doi: |0.| |77/|5579883|87765|3.

Ogbera, A. O. (2014) 'Diabetes mellitus in Nigeria: The past, present and future', World Journal of Diabetes, 5(6), p. 905. doi: 10.4239/wjd.v5.i6.905.

Ojifinni, O. O. and Ibisomi, L. (2020) 'Preconception care practices in Nigeria: a descriptive qualitative study', Reproductive Health, I7(1), p. 172. doi: I0. I |86/s I 2978-020-01030-6.

Olowokere, A. E., Komolafe, A. and Owofadeju, C. (2015) 'Awareness, Knowledge and Uptake of Preconception Care among Women in Ife Central Local Government Area of Osun State, Nigeria', Journal of Community Health \& Primary Health Care, 27(2), pp. 83-92.

Onasoga, A. O. et al. (20/4) 'Awareness and barriers to utilization of maternal health care services among reproductive women in Amassoma community, Bayelsa State', International Journal of Nursing and Midwifery, 6(I), pp. 10-15. doi: 10.5897/ijnm2013.0108.

Osuji, F. (2004) 'Paper presented by Professor Fabian Osuji, Honorable Minister of Education, Federal Republic of Nigeria', in 47th session of the International Conference on Education, 8-II September 2004. Geneva. Available at: www.ibe.unesco.org/international/ICE47/English/ Natreps/reports/Nigeria.

Patabendige, M. and Goonewardene, I. M. R. (20/3) 'Preconception care received by women attending antenatal clinics at a Teaching Hospital in Southern Sri Lanka', Sri Lanka Journal of Obstetrics and Gynaecology, (March), pp. 3-9.

Poels, M. et al. (20I7a) 'Healthcare providers' views on the delivery of preconception care in a local community setting in the Netherlands', BMC Health Services Research, 17(I), p. 92. doi: I0. II86/s I 29|3-0|7-205|-4.

Poels, M. et al. (2017b) 'Parental perspectives on the awareness and delivery of preconception care', BMC Pregnancy and Childbirth, I7(I), pp. 9-II. doi: |0.I |86/s|2884-0|7-|53|-I.

Poston, L. et al. (20/8) 'Before the beginning: nutrition and lifestyle in the preconception period and its importance for future health', The Lancet, 39I(10132), pp. I830-184I. doi: 10.1016/s01406736(I8)303II-8.

Segal, T. R. and Giudice, L. C. (2019) 'Before the beginning: environmental exposures and reproductive and obstetrical outcomes', Fertility and Sterility, ||2(4), pp. 6|3-62|. doi: I0.1016/j.fertnstert.2019.08.00I.

Shawe, J. et al. (2015) 'Preconception care policy, guidelines, recommendations and services across six European countries: Belgium (Flanders), Denmark, Italy, the Netherlands, Sweden and the United Kingdom', The European Journal of Contraception and Reproductive Health Care, 20, pp. 77-87. doi: 10.3109/| 3625|87.20|4.990088.

Stephenson, J. et al. (2014) 'How do women prepare for pregnancy? Preconception experiences of women attending antenatal services and views of health professionals', PLoS ONE, 9(7). doi: 10.1371/journal.pone.0103085.

Stephenson, J. et al. (2018) 'Origins of lifetime health around the time of conception: causes and consequences', The Lancet, 39I(10132), pp. |842-1852. doi: |0. I0|6/s0|40-6736(|8)303|2-x.

Strutz, K. L., Richardson, L. J. and Hussey, J. M. (20I4) 'Selected Preconception Health Indicators and Birth Weight Disparities in a National Study', Women's Health Issues, 24(I), pp. e89-e97. doi: 10.1016/j.whi.2013.10.001.

Temel, S. et al. (2015) 'Knowledge on preconceptional folic acid supplementation and intention to seek for preconception care among men and women in an urban city: A populationbased cross-sectional study', BMC Pregnancy and Childbirth, I5(I). doi: 10.1 I86/s |2884-015-0774y.

Tuomainen, H. et al. (20/3) 'Opportunities and challenges for enhancing preconception health in primary care: qualitative study with women from ethnically diverse communities.', BMJ Open, 3(7), pp. I-9. doi: I0. I | 36/bmjopen-20 I3-002977.

VERBI Software (20I7) 'MAXQDA 20I8'. Berlin, Germany: VERBI Software. Available at: https://www.maxqda.com.

Wekesah, F. and Izugbara, C. (20I7) 'Maternal Health in Nigeria: Facts and Figures', African Population and Health Research Centre Fact Sheet, (June), pp. I-4. Available at: http://aphrc.org/wpcontent/uploads/20 I/06/APHRC-20 I 7-factsheet-Maternal-Health-in-Nigeria-Facts-andFigures.pdf.

World Health Organization (20/2) Meeting to develop a global consensus on preconception care to reduce maternal and childhood mortality and morbidity, WHO Headquarters, Geneva Meeting report. Geneva, Switzerland.

World Health Organization (2013) WHO Global Action Plan for the Prevention and Control of Non- communicable Diseases 2013-2020. Available at: www.who.int/about/licensing/copyright_form/en/i ndex.html. 